\title{
Tariff Protection, Import Substitution and Investment Efficiency
}

\author{
by \\ RONALD SOLIGo \\ and \\ JOSEPH J. STERN*
}

“ $\because$. The import substitution effort will have to be intensified, particularly in capital goods and intermediate products, like base metals, chemicals, petroleum products and non-metallic minerals... The scarcity price of foreign exchange should be appropriately reflected to the economy so that there is an incentive to use less foreign exchange and more domestic resources. This will call for a revision in the present tariff policy..." [Third Five Year Plan, p. 35].

"... The second important element in the [balance of payments] strategy is to develop an import pattern which will encourage savings and investment and extend the import substitution effort to a much wider front." [Third Five Year Plan, p. 79].

\section{INTRODUCTION}

A chronic deficit in the balance of payments is a problem which plagues almost all developing countries. In Pakistan, as in other countries, the development plans have contained a two-pronged approach to the problem: to increase exports and to reduce the need to import through a process of import substitution. Exports have boen encouraged by giving numerous concessions and subsidies to the exporting firms ${ }^{1}$ but the best known and most successful of the export promotion schemes is the bonus voucher system ${ }^{2} \mathbf{3}^{3}$.

Industrialization has been pursued behind a wall of tariffs and import licensing which have provided generous incentives for the establishment in Pakistan of import-substituting industries. Within this framework of high protection to

*The authors are research advisor at the Pakistan Institute of Development Economics and advisor to the Planning Commission respectively. We are indebted to Drs. Nurul Islam and Bruce Glassburner, Director and Senior Research Advisor of the Pakistan Institute of Development Economies respectively and to Mr. Asbjorn Bergan, advisor to the Planning Commission for comments and suggestions which have considerably improved the study. The authors claim full responsibility for any remaining errors and the points of view expressed.

1 For a detailed description of the export promotion schemes which have been pursued in Pakistan since Partition, see, Hecox [2].

2 For a description and analysis of the bonus voucher scheme, see, Bruton and Bose [1].

3 The authors are preparing a second article dealing with the comparative profitability and efficiency of export industries. 
domestic industrios and stiff barriers to foreign competition, manufacturing industries in Pakistan have indeed grown at a rapid rate [13; 6]. Pakistan's Third Five Year Plan [11] has taken cognizance of the need to develop and extend the import substitution effort and, what is more, to use tariff policies to achieve this end.

The impressive gains which have taken place in industrialization under the protection of tariffs and licences have always been used to justify the tariff policy. Yet the complexities of the economic system are such that what appears to be beneficial may, when looked at from the view-point of the whole economy, be less of a gain than one is led to believe at first, and may even be a loss to the economy. The purpose of this study is to examine, in light of the available data, the effects of past protection on the efficiency of investment allocation and to make some estimate of the implicit protection given to domestic industries by the present tariff structure in the absence of quantitative cọntrols.

As is point ed out in Section II, the present tariff structure may have been inoprative in the past because of other trade barriers. But with sufficiently increased liberalization of imports it could become a major variable in determining the pattern of resource allocation in the future. Given the obvious need for import substitution if the target for reducing dependence on foreign aid is to bo realized, and the role that tariff policy must play in this effort, there can bo no doubt that a serious effort to understand the full implications of the present tariff policy is warranted.

\section{BACKGROUND TO THE PROBLEM}

Two factors make import substitution an extremely attractive development strategy. First, a policy of encouraging import-substituting industries will produce results quickly since it permits indigenous entrepreneurs to exploit existing markets rather than forcing them to develop new markets for domestically produced goods. Second, import substitution makes an obvious and direct effort to save foreign exchange by substituting imports of raw materials for final manufactures while simultaneously increasing domestic value added.

For a number of reasons, a policy of import substitution often favours the development of consumer-goods-oriented industries. First, the markets which exist in developing economies are primarily for consumer goods. There being little or no indigenous manufacturing initially, the market for intermediate or capital goods is small or non-existent. Second, consumer goods industries, by and large, require less capital investment than other industries, and often less skilled manpower, two factors which tend to be scarce in underdeveloped economies. Finally, in order to raise revenue for the public treasury and/or to economize on 
scarce foreign exchange by discouraging 'non-essential' imports, developing countries generally levy high import duties on consumer goods. Equivalent taxes are not usually levied on domestically produced consumer goods because such taxes would conflict with the policy of providing encouragement for domestic industries over imports. Domestic industry requires, at least initially, a subsidy to overcome lack of experience and capital. Such a subsidy is usually given in the form of high tariffs on competing imports with low taxes on domestic output and low tariffs on imported capital and industrial inputs.

It has been pointed out, first by Power [14] and Khan [4] and more recently by Radhu [15] that Pakistan's tariff structure has indeed given substantially more protection to consumer 'non-essential' industries than to intermediate and capital goods industries. However, Lewis and Qureshi [5] and also Radhu [15] have argued that the relative profitability of investment in different industries is affected as much by other government policies such as import licensing and the export bonus scheme as by indirect taxes and that these other factors have probably outweighed the tariff-created profit differentials. Lewis and Soligo [6] have more recently analyzed the available data on the production, imports, and exports of manufactured goods and have concluded that over the period 1954/55 to $1963 / 64$ import substitution has been equally important in both consumer goods and investment and related goods industries. In terms of percentage rates of growth, investment and related goods industries have grown faster than both intermediate and consumer goods industries. Intermediate goods industries have apparently grown more rapidly than consumer goods industries.

While the work done by Lewis and Soligo [6] shows that import substitution and growth of output have taken place more or less equally in consumer, intermediate and capital goods industries the question still remains: has import substitution proceeded too far in consumer goods industries? Has Pakistan used her scarce capital efficiently?

Power [14] and Khan [4] have argued that import substitution in consumer goods is not always a good thing. So long as consumer goods must be imported the extreme scarcity of foreign exchange acts as an effective constraint to the expansion of consumption. Once consumer goods industries have been established domestically, the discipline enforced by the supply of foreign exchange is to some extent removed. As the indigenous production of consumer goods increases, consumption is 'liberalized' and savings do not increase as quickly as they otherwise might. Ultimately, the rate of growth in real income will be lower when import substitution in consumer goods is permitted.

A second possible danger of import substitution is pointed out by Johnson [3] who notes that: 
... the excess cost of import substitution may be high, appreciably higher than is implied by the tariff rates or the excess of domestic over foreign prices. Progressive import substitution could therefore easily absorb or more than absorb the potential increase in real income that would normally accrue from technical improvements and capital accumulation, and permit a country to accumulate capital at a substantial rate without achieving a significant increase in real income or in real income per head.

Import substitution, in so far as it departs from the principle of comparative advantage, may saddle a country with high cost industries which can only survive behind a high protective wall. In fact, these industries may turn out to be so inefficient that the amount of protection that has to be provided to them is greater than their contribution in terms of value added.

In order to examine the issue raised by Johnson we must compute the implicit subsidy given to manufacturing industries in Pakistan by means of the tariff structure. As a country's tariff structure normally extends protection to intermediate products and raw materials as well as to final goods, the tariff acts as both a subsidy and a tax on domestic production. The tariff on competing imports of an industry allow the producer to raise the prioe of his product and in this respect the tariff is a subsidy to domestic production. On the other hand, the tariff on competing intermediate and raw material inputs allow the domestic suppliers of such products to raise their prices and in this sense the tariff is a tax on domestic production. The implicit subsidy is the amount of protection a producer gets from the tariff structure after allowing for the fact that tariffs act as both a subsidy and tax on domestic production. The residual obtained by subtracting this subsidy from the current value added in the industry measures the value added (the amount which could be paid to the domestic factors of production) if tariff protection were removed and assuming that foreign exchange was valued at its real opportunity cost.

If the new value added computed in the above manner is less than what would be necessary to pay capital and labour inputs their real scarcity price, we may conclude, excepting those cases in which the 'infant' industry argument is applicable, that investment in that particular industry is inefficient, at least at tho margin. Real income could, therefore, be increased by transferring resources from this industry to some other industry where factors of production are receiving their scarcity price.

As we point out in Section III, the above exercise is only correct under certain assumptions about the relationship of domestic prices to foreign prices. While these simplifying assumptions do not in fact hold for Pakistan, our results 
are such that, together with what information is available about the divergence of reality from our assumptions, we can draw some revealing and interesting conclusions regarding the efficiency of past allocation of capital and of the relative rates of protection to domestic value added inherent in the present tariff structure.

\section{METHODOLOGICAL FRAMEWORK AND SOURCES OF DATA}

As we have pointed out in the previous section, the purpose of this paper is to examine the available data from the viewpoint of drawing some conclusions about the efficiency of past investment and to evaluate the bias inherent in the present tariff structure as measured by the implicit subsidy given to domestic value added. Because of the disequilibrium in the market for foreign exchange and the distortion which results from import licensing, it is not possible to deal definitely with the issues we have raised. In order to show clearly what can be said about investment efficiency and tariff protection with the data at hand, we first analyze the data within the framework of a simplified model which embodies several restrictive assumptions. We then discuss what effect the relaxation of these assumptions will have on our results.

In what follows, we first develop a simplified model and then analytically relax the assumptions. This exercise will clarify the difference between what we would like to measure and what in fact we can measure with our data. In Section IV, where we present our results, we discuss what the relaxation of the assumptions would mean with respect to the data we have used.

What we wish to measure is the implicit subsidy which would be given to domestic industry as a result of tariffs, where in fact the tariff structure is a determinant of relative domestic prices. Under such conditions the subsidy is measured for each industry by taking the difference between what domestic factors of production receive in that industry with the given tariff structure (i.e., value added with the tariff structure) and what these same factors could be paid if the industry was required to operate within a framework of free trade, that is, where output was sold at 'world' prices and, similarly, inputs were purchased at 'world' prices.

Suppose the input-output structure for the ${ }_{i}$ th manufacturing industry is given by:

$$
\mathbf{X}_{\mathrm{i}}=\sum_{\mathrm{J}=1}^{\mathrm{n}} \mathrm{X}_{\mathrm{ji}}+\mathrm{W}_{\mathrm{i}}
$$

where: $X_{i}=$ gross value of output in domestic prices of ${ }_{i}$ th industry at factor cost.

$\mathrm{X}_{\mathrm{ji}}{ }^{\prime}=$ total deliveries from industry $\mathrm{j}$ to industry $\mathrm{i}$ measured in domestic prices. 
$W_{i}=$ value added in domestic prices of $i^{\text {th }}$ industry.

In order to measure the difference between actual value added, $W_{i}$, and what would be paid to domestic factors in the absence of trade barriers, we make two simplifying assumptions:

i) that the official exchange rate reflects the scarcity price of foreign exchange; and

ii) that the domestic price of any commodity is equal to the world price of a competing import plus domestic taxes on imports. That is.

$P_{d i}=P_{w i}\left(1+t_{i}\right)$

where: $\mathbf{P}_{\mathrm{di}}=$ the domestic price for commodity $i$;

$\mathbf{P}_{w i}=$ the 'world' price for commodity $i$, converted at the official exchange rate; and

$t_{i}=$ the tariff rate on commodity $i$.

We define:

$$
V_{i}=Y_{i}-\sum_{j=1}^{n} Y_{j i}
$$

where: $Y_{i}=$ the gross value of output of industry $i$ at 'world' prices;

$Y_{j i}=$ the value of the inter-industry deliveries from industry $j$ to industry $i$, expressed in 'world' prices;

$V_{i}=$ measures the amount which could be paid to domestic factors of production in industry $i$ if the output were sold, and inputs purchased, at 'world' prices, all converted at the official rato of exchange.

Using assumptions $i$ ) and $i$ ) wo have the following relationship between the variables in Equations (1) and (3):

$$
\begin{aligned}
& X_{i}=Y_{i}\left(1+t_{i}\right) . \\
& X_{i i}=Y_{j i}\left(1+t_{j}\right)
\end{aligned}
$$

Substituting (4) into (3) we have:

$$
v_{i}=\frac{x_{i}}{\left(1+t_{i}\right)}-\sum_{i=1}^{m} \frac{x_{i i}}{\left(1+t_{i}\right)}
$$

It should be noted that $V_{1}$ does not measure the amount which could be paid to domestic factors of production after all trade barriers were eliminated and the economy were permitted to find a new equilibrium position in terms of the exchange rate, relative prices, and so on. Rather, $V_{i}$ measures the payments to domestic factors which would be possible given the existing technology, as represented by the input-output coefficients, and the existing opportunity price 
of foreign exchange. This concept of $V_{i}$ is the appropriate one, since wo wish to determine the relative efficiency of domestic industries with the present technology and exchange rate.

The subsidy implicit in the tariff structure would then be given by:

$$
\mathbf{W}_{i}-\mathrm{V}_{\mathbf{i}}
$$

To make inter-industry comparisons one should compare the absolute subsidy as measured by Eq"n tion (6) with total value added. Hence, we dęfine:

$$
U_{i}=\frac{W_{i}-V_{1}}{W_{i}} \ldots \ldots \ldots . . . . . . . .
$$

where $U_{i}$ measures the proportion of domestic value added in current domestic prices which is subsidized by the tariff structure and, in this sense, is a measurement of the implicit rate of protection given to domestic value added by the tariff structure.

Equations (5) through (7) would permit us to evaluate the impact of the tariff structure provided the assumptions made above are correct. Unfortunately assumptions $i$ ) and $i$ ) are not valid for Pakistan. It is well known and has been demonstrated by Pal [12] that at the official rate of exchange there exists a scarcity margin on imports. That is to say, the present official exchange rate overvalues the rupee. Because of excess demand for foreign exchange at the official exchange rate, the available foreign exchange is allocatod by means of import licensing ${ }^{4}$ with the result that the scarcity margin for imports and competing domestic output will be different for each commodity.

Very little is known about the scarcity margin aside from Pal's study. He found that the margin did vary from commodity to commodity but, on the average, the scarcity margin on consumer goods was the same as on investment goods. Pal was concerned only with prices of imported goods and hence his study throws no light on those cases where the import taxes are so high that competing imports are completely absent from the market. In those cases, or where there is an outright embargo on imports, the domestic price could well be below the c.i.f. price plus import tariffs. Unfortunately, there is no information to either support or refute this proposition. We are, however, inclined to believe that there is likely to be excess demand in all commodity markets and, that as a minimum, domestic price does equal c.i.f. price and import taxes. That is to say that at best the scarcity margin is zero. This assumption is maintained throughout what follows.

How would the relaxation of assumptions $i$ ) and $i$ ) affect the results computed from Equations (5) to (7)? First, let us assume that although there is dis-

4 See, Naqvi [7] for a description of the import licensing system. 
equilibrium in the foreign exchange market, the scarcity premium is equal for all commodities. Such a situation would arise if foreign exchange were auctioned and no controls were imposed on the composition of imports.

If this were the case, the $V_{i}$ computed by Equations (5) to (7) would represent $V_{i}$ at the true scarcity price of foreign exchange and not at the official rate of exchange. This would still be the appropriate measure of $V_{i}$ since it measures $V_{i}$ at the current opportunity cost of foreign exchange. Similarly, $U_{i}$ computed from this $V_{i}$, would be the 'correct' measure of the implicit protection given to domestic value added by the tariff structure. If one wished to measure the rate of protection given by both the tariff and the overvalued exchange rate then one should deflate $V_{i}$ by the extent of overvaluation. Suppose that $S$ is the scarcity margin, then this would change Equation (5) to:

$$
V_{i}^{\prime}=\frac{X_{i}}{\left(1+t_{i}\right)(1+S)}-\sum_{j=1}^{n} \frac{X_{j i}}{\left(1+t_{i}\right)(1+S)}=\frac{V_{i}}{(1+S)}
$$

and Equation (7) to:

$U_{i}^{\prime}=\frac{W_{i}-V_{i}^{\prime}}{W_{i}}=W_{i}-\left[\frac{V_{i}}{(1+S)}\right]$

The extent of the subsidy involved, and hence the absolute value of $U_{i}$, is a function of the scarcity margin. However, if $S$ is equal for all industries, the ranking of the industries by $U_{i}$ is not affecte ${ }^{*}$ by the value of the scarcity margin.

Let us now assume, as is in fact the case, that the scarcity margin is different for each commodity. Calculating $V_{i}$ from Equation (5) now gives the amount which could be paid to domestic factors of production taking into account the vector of scarcity prices of foreign exchange which prevail. That is, $V_{i}$ would measure the amount which could be paid to domestic factors under a multiple exchange rate system, where the exchange rate for each commodity is equal to the present official exchange rate plus the scarcity margin on that commodity.

The amount which could be paid to domestic factors at the current official exchange rate if both tariffs and licensing protection were withdrawn would be:

$$
V_{i}{ }^{\prime \prime}=\frac{X_{i}}{\left(4+v_{i}\right)\left(1+S_{i}\right)}-\sum_{j=1}^{n} \frac{X_{i j}}{\left(1+t_{j}\right)\left(1+S_{j}\right)}
$$

where $S_{i}$ and $S_{i}$ are the scarcity margins on the ${ }_{i}$ th and ${ }_{j}$ th commodity respectively.

In what follows we have computed $V_{i}$ and $U_{i}$ using Equation (5) and on this basis draw some conclusions about the relative ranking of $V_{i}$ and $U_{i}$ as if they had been calculated by Equation ( $\left.5^{\prime \prime}\right)$. 
We feel that there is some justification for making the jump from Equation (5) to Equation (5") because a) the data we use give imported inputs at c.i.f. prices. This means that for these intermediate inputs we do not need to know either $t_{j}$ or $S_{j}$ to compute their value at world prices (at the official rate of exchange); and $b$ ) domestic intermediate deliveries are predominantly either commodities which are also exported, such as raw cotton and jute, and for which the scarcity margin is zero, or services which cannot be traded in the international markets and, hence, for which 'world' prices are irrelevant.

The net result of $a$ ) and $b$ ) is that the proportion of intermediate inputs for which we need to know the value of the scarcity margin is small and that the bias in the value of $V_{i}$ and $U_{i}$ computed on the basis of Equation (5) is primarily determined by $S_{i}$, the scarcity margin on the output of the industry. Since Pal [12] shows that as a group the scarcity margin is the same for consumer goods and investment goods, our comparison of these two groups of industries, using $\mathbf{U}_{i}$, is reasonable. Within groups, the ranking of industries on the basis of the computed $V_{i}$ and $U_{i}$, will differ from the 'true' ranking, that is to say the ranking which we would derive from our results if we had all the required data, depending on the extent to which the scarcity margins on the output of these industries differ.

Data on the inter-industry relationships in Pakistan are available from the Tims-Stern input-output table ${ }^{5}$ [10] prepared for the Planning Commission. Explicit rates of tariff, $t$, nd $t_{j}$ have been derived from Radhu [15]. These estimates were modified in the following way ${ }^{6}$. First, Radhu's estimates are simple arithmetic averagos of duties for all commodities within a group. Rather than accept these broad averages, we have $i$ ) in the case of outputs taken the duties on only those commodities which are actually produced in Pakistan and ii) in the case of intermediate inputs, we have taken the rates of duty only on the specific inputs used in any given industry. Rates of duty on specific commodities have been taken from the Pakistan Customs Tariff Manual [9], while detailed information on the composition of outputs and inputs for each industry is available from the Census of Manufacturing Industries [8]. Secondly, Radhu's estimates include sales taxes in addition to import tariffs. Since we are working with output at factor cost we have added the sales taxes only in those cases where domestic production is exempted from them. In those cases the sales tax acts as additional

5 The framework of the Tims-Stern input-output table and the equations used to calculate the results are shown in Appendix A.

6 We wish to express our appreciation to Mr. Ghulam Mohammad Radhu for assisting us in revising some of the average rates of duty and for guiding us through all the manifold intricacies of the indirect tax structure. Although we have tried to take account of all the duties and taxes, inclusions and exclusions, the responsibility for any remaining errors rests exclusively with the authors. 
tariff protection since they are levied only on competing imports. Finally, Radhu's data deal with the tariff structure as of $1962 / 63$. We have incorporated the few changes in import duties and sales taxes which have become effective in 1963/64.

\section{ESTIMATES OF TARIFF PROTECTION AFFORDED TO VALUE ADDED}

In this section we discuss the significance of our computed $U_{i}$ coefficients, compare them to other variables and parameters and suggest some possible qualifications of our results.

We have computed $U_{i}$ (the ratio of net subsidy from tariffs to value added) for some forty-eight manufacturing industries. These are shown in Table I.

In three industries, grain milling, rice milling and printing and publishing, the protection given to value added is negative, or, what is the same thing, the net effect of the tariff structure is to tax the output of these industries. This is not surprising in view of the fact that in all three cases the explicit rate of tariff protection given to the putput $\phi f$ the industry is zero while tariffs are levied on inputs used in these industries.

In all other cases $U_{i}$ is greater than zero; that is, the rate of tariff on output is sufficiently high to more than offset the addition to cost which arises from the protection given to the suppliers of inputs. For these industries the net effect of the tariff structure is to subsidize their value added; to permit them to pay a higher return to labour and capital than they would be able to pay if exposed to unfettered world competition.

\section{TABLE I}

\section{IMPLICIT RATE OF PROTECTION OF VALUE ADDED}

\section{Consumer Goods}

i) Food, beverages and tobacco

Canning and preserving

Grain milling

Rice milling

Bakery product

Sugar

Edible oils and fats

Tea

Salt

Beverages (non-alcoholic)

Cigarettes
$\mathrm{U}_{\mathrm{i}} \quad$ Intermediate Goods

Jute textiles

Dyeing and finishing

1.21 Rubber products

0.18

1.15 Fertilizers

2.02. Paints and varnishes

0.45 Pharm. and chem. nec.

0.78 Petroleum and coal products

1.08 Paper products 
ii) Textiles, wearing apparel and footwear

Cotton textiles

Woollen textiles

Silk and art silk

Knitting

Footwear

Wearing apparel

Investment and related goods

Metal furniture

1.52 Non-metallic products

0.46

1.46 Cement $\quad 0.58$

1.41 Basic metals $\quad 0.58$

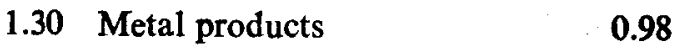

1.04 Non-elect. machinery $\quad 0.11$

2.17 Sewing machinery $\quad 0.78$

Electrical appliances $\quad 0.67$

iii) Other Consumable Goods

Electrical machinery

0.25

Other transp.

0.33

Wood products (furniture) 1.84 Motor vehicles

Printing and publishing

-0.15 Cycles

1.61

Leather goods

1.12

Soaps, perfumes and

cosmetics

0.64

Matches

0.92

Optical goods

0.31

Plastic goods

0.77

Sports goods

0.48

Pencils and pens

0.39

There are considerable inter-industry differences in the rates of protection given to value added. In general $i$ ) consumer goods are much more heavily protected than either intermediate or investment and related goods, ii) within the consumer goods industries, non-essentials, such as beverages and cigarettes, are much more heavily protected than essential industries such as grain and rice milling, salt and tea, iii) textiles are the most heavily protected group of industries, although the protection is approximately the same for all components of the group and iv) the least protected industries are those producing heavy machinery, both electrical and non-electrical, and transport equipment other than motor vehicles and cycles. Fertilizer is also among the least protected group.

In twenty-three industries, the coefficient $U_{i}$ is greater than unity. For these industries, the net subsidy received through tariff protection exceeds the total value added! These results are surprising particularly because these industries are $i$ ) primarily consumer goods industries and $i i)$ include very large industries (in terms of value added) such as cotton and jute textiles, sugar, tobacco and coal and petroleum products. 
What is the meaning of $U_{i}$ greater than unity? From our definition of $U_{i}$ it is readily apparent that $U_{i}>1$ implies that $V_{i}$ is negative. From Equation (7) we have:

$$
\begin{aligned}
& U_{i}=\frac{W_{i}-V_{i}}{W_{i}} \\
& \text { or } \\
& U_{i}=1-\frac{V_{i}}{W_{i}}
\end{aligned}
$$

$V_{i}$ measures the amount which could be paid to capital and labour if output was sold and those inputs which can be traded were purchased at 'world' prices when converted at the official rate of exchange. A negative $V_{i}$ means that the total cost of intermediate inputs valued at their 'world' prices, or at their domestic price if they cannot be traded ${ }^{7}$, exceeds the value of output when expressed in 'world' prices. $V_{i}$ could then be negative for two reasons: $i$ ) intermediate inputs are used more inefficiently in Pakistan than in other countries. There may be more wastage of raw materials and services in Pakistan due to poor maintenance of machinery, inefficient quality control or lack of alternative uses for scrap, waste and some by-products because transport costs may be too high to permit these to be disposed of profitably. $i$ ) The price of domestically produced services, which cannot be imported, may be higher than the price of similar services in other countries. Electricity and motorized transport are two particular examples where cost per unit output are probably higher than in other countries ${ }^{8}$. If this be so, then our conclusions would indicate that Pakistan should not invest in those industries which are intensive users of these inputs.

Whatever factors are the cause, a negative $V_{i}$ is nevertheless surprising for it is equivalent to saying that the average revenue product of capital and labour is negative.

Efficient resource allocation (in the static sense) requires that the marginal revenue product of capital and labour, when measured in terms of 'world' prices, be equal in all industries. In our study we have computed only the average product of labour and capital and hence, we cannot make inter-industry comparisons of the marginal productivities. We can, however, draw some important conclusions for those industries where the average product of labour and capital is negative and from these conclusions make some broad inferences about the remaining industries as well.

7 We assume that at the given supply, the current domestic price of these inputs are equal to their scarcity price.

8 At least this is often alleged to be the case by industrialists. An international comparison of these costs, although not within the scope of this paper, would be extremely interesting and would throw considerable light on our findings. Although we have not attempted to The rank correlation coefficient between the $U_{i}$ and the cost of electricity, gas, water and all other services was insignificant. Nevertheless for some specific industries the cost of electricity, gas, water and services may be a contributing factor to the negative $V_{i}$. 
MUANeE REVENUE AND

MARINAL REVENUE PRODUCT

IN WOALO PRICES

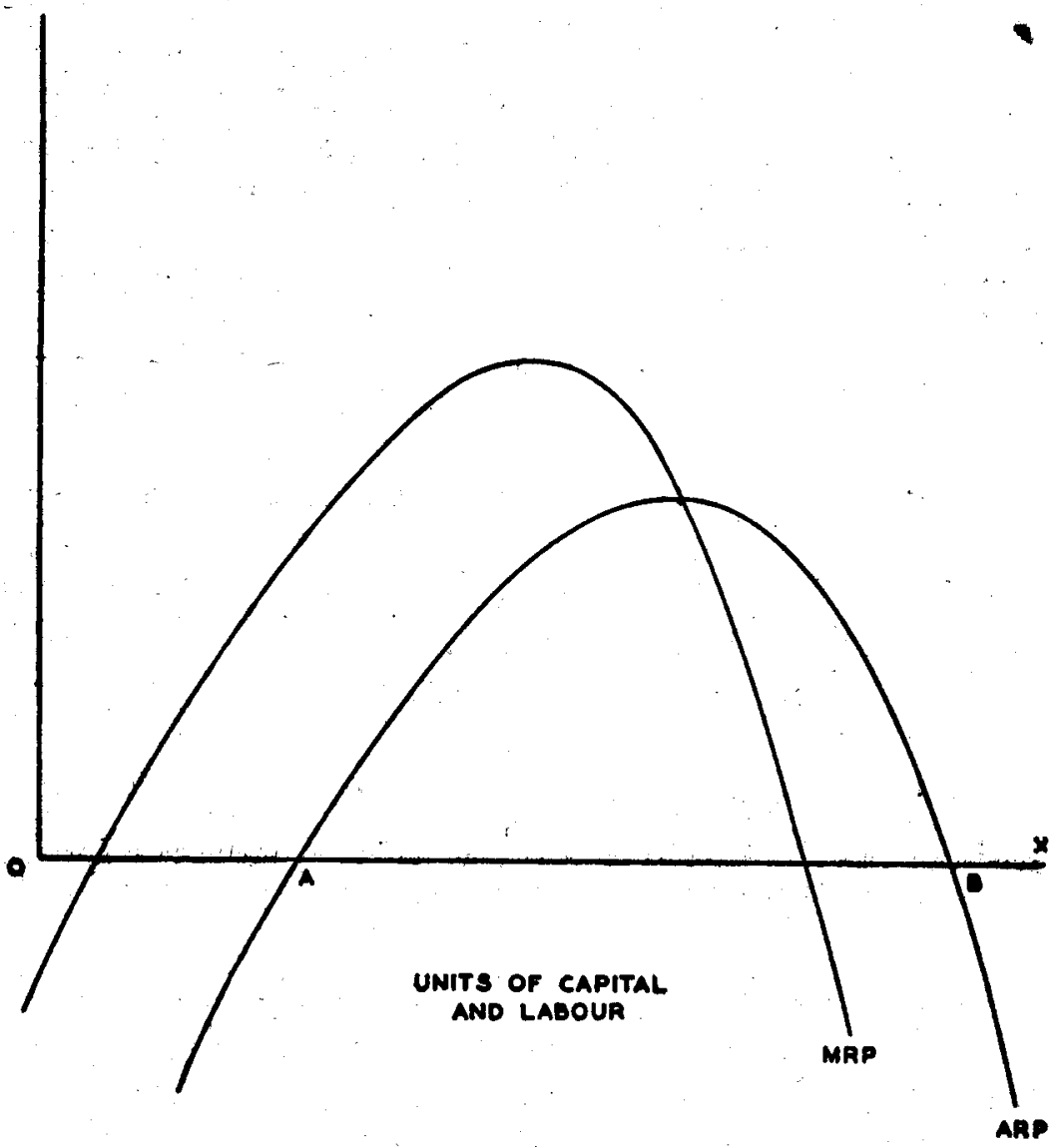

Figure 1. 
Figure 1 shows the conventional diagram of average and marginal revenue product curves for a given industry measured in terms of world market prices. The curves represent long run curves with capital as well as labour a variable factor. On the horizontal axes we plot the composite of capital and labour which is the optimum, given the wage and interest rates, for the corresponding scale of output.

There are two distinct cases where the average product of capital and labour is negative: Case (i), if output is less than OA, the average revenue product is negative but the marginal product is positive?. Industries which fall into this category are 'decreasing cost' industries or are at least in the decreasing cost portion of their cost curves, so that both marginal and average productivity would increase as output increased. Case (ii), if output is greater than OB both average and marginal products are negative. These industries have clearly been overexpanded. A third case may also be distinguished. The standard 'infant industry' argument is that even if an industry has a sufficiently large market to allow it to operate efficiently in the short run and has potentially a comparative advantage, the industry will need a subsidy to enable it to acquire experience and knowhow, to train its labour force and to establish markets. Essentially, the argument is that the industry needs time to get on to the long run curves shown in Figure 1. At first the industry is operating at points below the curves, regardless of the scale of output, but with experimentation and experience the industry will eventually be able to raise productivity of capital and labour to that achieved in other countries.

The 'infant industry' argumont can be applied to industries with both increasing and decreasing marginal products. Hence, if the average product of capital and labour is negative, the marginal product can be either positive or nogative.

Wherever the marginal revenue products of capital and labour are below their opportunity costs, resources have been misallocated. If the industry falls into Case (i) then the establishment of the industry was premature. Investment should have been postponed until the size of the market was sufficiently large to permit an efficient scale of operation. Real income could presently be increased by abandoning the industry and importing the final products from abroad. If the industry falls into Case (ii) the industry has been over expanded. Real income could be increased by shifting resources at the margin out of this industry into other uses. In both cases real income would increase even if the displaced capital and labour were not re-employed elsewhere.

9 Marginal product must be either positive or zero; otherwise it would pay to reduce output to zero. 
Only in the case of the "infant industries" can one argue that the past allocation of investment was in any sense efficient.

The data in Table I suggests that the following industries a*e cases of either over-expansion, premature investment or of an infant industry:

aie.c.

i) all food, boverages and tobacco except grain and rice milling, tea and salt;

ii) textiles, footwear and wearing apparel;

iii) lea ther and leather goods;

tv) wood and wood products;

v) motor vehicles, cycles and metal furniture.

Some of these industries may be genuine cases of 'infant industries' and our conclusions should be modified accordingly. On the other hand, looking at the list of industries in Table $I$. it is clear that most of the industries with negative average product of labour and capital, that is with $U_{i}>1$ are not likely candidates for the 'infant industry' argument. Most of the largest industries in Pakistan are in this group while many of the investment goods industries which are relatively very small compared to other industries in Pakistan and to their counterparts in other countries, have positive average product for capital and labour.

In terms of general categories of industries, investment has been either premature or over-extended. primarily in consumer goods industries.

Power [14] and Khan [4] have criticized tariff, tax, import licensing and other policies which affect the pattern of investment on the grounds that they have permitted a too rapid expansion of consumer goods industries which in turn has led to 'consumption liberalization', and reduced savings and growth in real income. Our results indicate that in addition to the effects on real income growth through reduced savings, the investment in consumer goods industries have reduced growth in real income because, at wortd market prices, the marginal productivity of domestic capital and labour is below their opportunity cost and may even be negative. )

Our data also indicate that the most productive use of capital in the future lies in the investment and related goods industries. These industries have been able to survive, and indeed grow rapidly, with only relatively modest tariff protection. It is clearly in these industries in which Pakistan has a comparative advantage, which she should now go on to exploit. Our study, of course, has only compared the tariff protection given to different manufacturing industries. We have not compared the manufacturing sector as a whole with other sectors such as agriculture or mining. Our conclusions refer only to the relative pro- 
fitability of different industries within the manufacturing sector. It may well be that investment in manufacturing as a whole is less productive than in other sectors.

\section{Some Qualifications}

In what follows we will try to anticipate some of the objections of the skeptics. We discuss some of the characteristics of the data and methodology which may have biased our results.

The equation used to compute $V_{i}$ can be expressed as follows:

$$
V_{i}=\frac{x_{i}}{\left(1+t_{i}\right)}-\sum_{j=1}^{n} \frac{x_{j i}}{\left(1+t_{j}\right)}
$$

and $U_{i}$ is given by:

$$
U_{i}=\frac{W_{i}-V_{i}}{W_{i}}
$$

As we have pointed out in Section III, the results as computed from Equation (5) assumes that $i$ ) the official exchange rate is an equilibrium rate or $i$ ) if the official rate is not an equilibrium rate then the scarcity margin is equal on all commodities and iii) that the domestic price of each commodity is at least equal to the c.i.f. price of a competing import converted at the official exchange rate plus import taxes.

We accept assumption iii) as being reasonable; we know however that both i) and ii) are incorrect. We have already pointed out the bias in our results because we fail to take account of the scarcity margin on the outputs of each industry and on the domestically produced intermediate inputs which can be traded. If we knew what the scarcity margins were, and included them in our calculation, the computed value of $V_{1}$ would be affected as follows:

a) the higher the scarcity margin on the output of the industry the lower would be the computed value of $\mathrm{V}_{1}$; and

b) the higher the scarcity margin on the domestically produced inputs, the higher would be the computed value of $\mathrm{V}_{\mathrm{i}}$.

We have previously pointed out that the proportion of total intermediate inputs which are both domestically produced and receive protection through import licensing is very small. Hence, unless the scarcity margin on these inputs is substantially higher than the scarcity margin on output, it is clear that it is the latter which will be the major determinant of any bias in our measured values of $V_{i}$ and $U_{i}$.

If in fact the bias in our $V_{i}$ is primarily the result of neglecting the scarcity margin on the output, then our $V_{i}$ will be, in general, too high, that is, if we 
could take the scarcity margin into account, the effect would be that our computed $V_{i}$ would be smaller than the one we now have and the new $U_{i}$ would be greater than those we have calculated. Some $V_{i}$ which were previously positive would now become negative and the whole ranking of the industries by $V_{i}$ and $U_{i}$ would change depending on the relative magnitudes of the scarcity margin. We should mention again however that Pal's study [12] does indicate that the average scarcity margin on consumer goods is the same as that on capital goods. Hence, the ranking of these two groups of industries with respect to each other would not change. Consumer goods industries would still be more heavily protected than investment and related goods industries.

$U_{1}$ will be biased upward if the actual value added, $W_{1}$, is underestimated. The underestimation of value added has been a consistent problem in the Censuses of Manufacturing Industries. Tims-Stern [10] have made some estimates of the downward bias in the magnitude of value added and have adjusted the data to allow for this. Their correction may, however, be insufficient, although there is no reason to believe that their figures would understate value added in such a way as to give $U_{1}>1$ primarily for consumer goods industries.

We conclude, therefore, that our estimates of $V_{i}$ and $U_{i}$ can be taken as a first approximation given the paucity of data on scarcity margins, inter-industry relations, and the value added by industries. It will only be in the light of further information on these variables that a final judgment on the questions raised in this study can be made.

\section{v. SUMMARY AND CONCLUSIONS}

The conclusions which can be drawn from this study are as follows. First, we have found that the implicit rate of protection to value added inherent in the present tariff structure is higher for consumer goods industries than for investment and related goods industries. In this regard our finding re-confirms what Radhu [15] found when he examined the explicit tariff structure. Apparently the effect of tariff protection on the inputs of intermediate goods are not suffciently different for consumer and investment goods industries to affect the relative amount of protection afforded these industries when measured by explicit and implicit rates. Our second conclusion refers to those industries for which we obtain $U_{i}>1$. This implies that the amount of protection exceeds the contribution to value added that the industry makes. We have argued that this may occur for three reasons: 1) the domestic market for the output of an industry may be so small that the industry cannot avail itself of the internal economies of scale and it therefore operates with high per unit costs. It may also be that the investment in certain industries is 'lumpy' in the sense that even the minimum size plant has a minimum cost output greater than what the domestic market 
can absorb. Here again the industry will exhibit a high per unit cost. In either case the implication is that the industry was established before it was oconomically warranted; 2) the industry may still be an 'infant industry' and thus the observed $U>1$ is a short run phenomenon which will persist until the industry can avail itself of external economies; and 3) protection may have made investment in some industries so profitable that there has been excess investment in some industries.

Our data do not allow us to make a clear choice between these three alternatives. However, the fact that $U_{i}>1$ is observed for many of the consumer goods industries, which one would feel reluctant to classify as either infant industries or industries suffering from too small a market, leads us to conclude that allocation of investment has been too much in favour of consumption. Thus, although investment in investment and intermediate goods industries have kept pace with investment in consumer goods industries there has been relatively too much investment in consumer goods industries. At the margin these industries are contributing nothing to the domestic economy and indeed are probably a drag on the growth of real income since:

i) not only are they using resources which could be used with greater marginal products elsewhere; but

ii) they may also have negative marginal products!

Our results lend strong support to the point of view expressed in the Third Five Year Plan [11] that the time has come to give priority to investment in intermediate goods and capital and related goods industries. Further, the investment in consumer goods industries should be encouraged only where it is clear that the industry can be reasonably efficient compared to alternative investment projects. In order to achieve the kind of investment allocation which is most desirable, a thorough overhaul of the tariff and tax policies is called for. Reforms are particularly urgent because the recent trend toward liberalization of imports, if continued, will increase the importance of tariffs in determining relative prices and the pattern of resource use. We have shown that even in the past, when the potentially distorting effects of the tariff structure were neutralized by import licensing and other direct controls, the pattern of investment has been wastefully biased towards consumer goods industries. When the neutralizing influences of direct controls are removed and the existing tariff structure becomes one of the major determinants of relative prices and relative profitabilities, Pakistan could be subjected to a period of wasteful and inefficient investment in additional consumer goods industries.

The conclusions which emerge from this study must of course be viewed in the context of the simplified model used and the data available. We have pointed 
out the major biases in our results which can be ascribed to our simplifying assumptions. It has been noted that our conclusions are not likely to be significantly affected if we were able to take into account the effects of the import licensing system.

The issues which our results raise are, however, of sufficient importance to warrant further discussion and investigation of whole matter of investment strategy and the comparative efficiency of investment in various domestic industries. Too often investment choices in developing economies are made on the basis of the simple yardstick of how much such investment will contribute to import substitution. To do so runs the risk of neglecting industries in which the country has a comparative advantage. The results may be growth in manufactured output without growth in real income. Our results indicate that this may in fact have been the result in Pakistan.

\section{Appendix A}

The equations in Section III have been developed for expositional purposes. The actual data available differ slightly from what is usually available from an input-output table and hence the particular equations we use to compute $U_{i}$ will also differ. In what follows we derive the equations which have been used to calculate $\mathbf{U}_{\mathbf{i}}$.

The Tims-Stern input-output model for the year 1963/64 [10] which we have used as the basic data source, is of the following form:-

$$
\sum_{j=1}^{n} X_{j i}+M_{i}+T_{m_{i}}+W_{i}=X_{i}
$$

where: $X_{j i}$ is the domestic deliveries from industry $j$ to industry $i$ measured in current domestic prices;

$\mathbf{M}_{\mathbf{i}}$ is the total imported inputs into industry i measured at c.i.f. prices;

$\mathbf{T}_{\mathbf{m}_{\mathbf{i}}}$ is the total indirect taxes paid on imported inputs into industry $\mathrm{i}$;

$W_{1}$ is the value added in industry $i$, measured in domestic prices;

and $\mathrm{X}_{\mathrm{i}}$ is the gross value of output of industry $\mathrm{i}$ at factor cost measured in domestic prices.

Imports are already given in world market prices but the value of outprt and domestic intermediate deliveries must be converted from domestic prices to international prices. The assumption which we have used to convert flows in domestic prices to world prices is that the domestic price for any given commodity is equal to the wo.ld price of a similar commodity plus Pakistan import taxes ${ }^{10}$. This assumption can be formalized as follows:

10 The assumption is discussed fully in Section III. 


$$
X_{i}=Y_{i}\left(1+t_{i}\right)
$$

where $Y_{i}$ is the gross value of output at factor cost of commodity $i$ measured in international prices and $t_{i}$ is the explicit rate of protection given to industry $i$. Similarly:

$$
X_{j i}=Y_{j i}\left(1+t_{j}\right)
$$

where $t$ is the tariff rate on commodity $j$ and $Y_{j i}$ is the value of deliveries from industry $j$ to industry $i$ measured in international prices.

Substituting Equations (2) and (3) into Equation (1) we have:

$$
\sum_{j=1}^{n} Y_{j i}+\sum_{j=1}^{n} Y_{j i} t_{j}+M_{i}+T_{m_{i}}+W_{i}=Y_{i}+Y_{i} t_{i}
$$

We define:

$$
\mathrm{V}_{\mathbf{i}}=\mathrm{Y}_{\mathbf{i}}-\left\{\sum_{\mathrm{J}=1}^{\mathrm{n}} \mathrm{Y}_{\mathrm{ji}}+\mathrm{M}_{\mathrm{i}}\right\}
$$

where $V_{i}$ is the amount which could be paid to domestic factors of production in industry $i$ if all tariffs were reduced to zero. $V_{i}$ is the residual when total intermediate deliveries are deducted from gross value of output, both expressed in international prices.

Substituting Equation (5) into Equation (4) and transposing some terms, we obtain:

$$
W_{i}=Y_{i} t_{i}-\left\{\sum_{j=1}^{n} Y_{j i} t_{j}+T_{m i}\right\}+V_{i}
$$

The expression : $Y_{i} t_{i}-\left(\sum_{j=1}^{n} Y_{j i} t_{i}+T_{m_{i}}\right)$ measures the net subsidy given to domestic value added by the tariff structure. The first part of the expression, $\left(Y_{i} t_{i}\right)$ is the additional revenue which the domestic manufacturer receives as a result of the higher prices for his output, made possible by the tariffs levied against competing imports. The second part $\left(\sum_{\mathrm{J}=1}^{n} Y_{\mathrm{jij}} \mathrm{t}_{\mathrm{J}}+\mathrm{T}_{\mathrm{m}_{\mathrm{i}}}\right)$ is the additional cost to domestic manufacturers due to tariffs on imported inputs and to the higher prices of domestic inputs which result from the tariff protection given to domestic producers of competing inputs. The amount paid to domestic factors of production $W_{j}$ is the sum of the payments which would be possible in the absence of trade barriers plus the net subsidy received as a result of the tariff structure.

To make inter-industry comparison of the degree of protection implicit in the tariff structure we compare the net subsidy given to each industry with Wi. We define: 
Soligo and Stern: Tariff, Imports, and Investment Efficiency

$$
U_{i}=\frac{W_{i}-V_{i}}{W_{i}}
$$

or

$$
U_{i}=\frac{Y_{i} t_{1}-\left(\sum_{j=1}^{n} Y_{j 1} t_{i}+T_{m_{i}}\right)}{W_{i}}
$$

$U_{i}$ measures the proportion of domestic value added which is subsidized by the tariff structure.

Substituting Equations (2) and (3) into Equation (8) we obtain:

$$
U_{i}=\frac{X_{i} \frac{t_{i}}{1-t_{i}}-\left\{\sum_{j=1}^{n} X_{j i} \frac{t_{j}}{1+t_{j}}+T_{m_{i}}\right\}}{W_{i}}
$$

